\title{
LYAPUNOV-TYPE INEQUALITY FOR FRACTIONAL BOUNDARY VALUE PROBLEMS WITH HILFER DERIVATIVE
}

\author{
NIMISHA PATHAK
}

Abstract. In this work, we establish Lyapunov-type inequalities for fractional boundary value problems containing Hilfer derivative of order $\alpha, 1<\alpha \leqslant 2$ and type $0 \leqslant \beta \leqslant 1$. We consider the boundary value problems with the Dirichlet, and a mixed set of Dirichlet and Neumann boundary conditions. We consider both integer and fractional order eigenvalue problems, determine a lower bound for the smallest eigenvalue using Lyapunov-type inequalities, and improve these bounds using semi maximum norm and Cauchy-Schwarz inequalities. We use the improved lower bounds to obtain intervals where a certain Mittag-Leffler functions have no real zeros. Further, we discuss the particular cases for the type $\beta=0$ and $\beta=1$, which give the results respectively for Riemann-Liouville and Caputo fractional boundary value as well as eigenvalue problems. For both the fractional and the integer order eigenvalue problems, we give a comparison between the smallest eigenvalue and its lower bounds obtained from the Lyapunov-type, semi maximum norm and Cauchy-Schwarz inequalities. Results show that the Lyapunov-type inequality gives the worse and semi maximum norm and Cauchy-Schwarz inequalities give better lower bound estimates for the smallest eigenvalues.

Mathematics subject classification (2010): 34A08, 34A40, 26D10, 33E12.

Keywords and phrases: Lyapunov inequality, Hilfer fractional derivative, Green's function, Laplace transforms, Mittag-Leffler function.

\section{REFERENCES}

[1] R. C. Brown And D. B. Hinton, Lyapunov inequalities and their applications, in Survey on classical inequalities, Math. Appl. 517, Kluwer Acad. Publ. Dordrecht. (2000), 1-25.

[2] J. S. DUAN, Z. WANGC AND Y. L. LIU, X. QIU, Eigenvalue problems for fractional ordinary differential equations, Chaos Solutions Fract. 46 (2013), 46-53.

[3] R. A. C. FerReIRA, A Lyapunov-type inequality for a fractional boundary value problem, Fract. Calc., Appl. Anal. 16, 4 (2013), 978-984.

[4] R. A. C. FERreIRA, On a Lyapunov-type inequality and the zeros of a certain Mittag-Leffler function, J. Math. Anal. Appl. 412, 2 (2014), 1058-1063.

[5] R. A. C. FERREIRA, Lyapunov-type inequalities for some sequential fractional boundary value problems, Adv. Dyn. Syst. Appl. 11, 1 (2016), 33-43.

[6] R. Gorenflo, J. LoutchKo And Y. Luchko, Computation of the MittagLeffler function $E_{a ; b}(z)$ and its derivative, Fract Calc Appl Anal. 5 (2002), 491-518.

[7] John W. Hanneken, B. N. Narahari Achar and David M. Vaught, An Alpha-Beta Phase Diagram Representation of the Zeros and Properties of the Mittag-Leffler Function, Hindavi Publl. corporation, Advances in Mathematical Physics, Article ID 421685 (2013), 13 pages.

[8] H. J. Haubold, A. M. Mathai And R.K. SAXena, Mittag-Leffler functions and their applications, J. Appl. Math., Article ID 421685 (2013), 13 pages.

[9] R. Hilfer, Y. LuCHKo AND Ž. TOMOVSKI, Operational method for the solution of fractional differential equations with generalized Riemann-Liouville fractional derivatives, Fract. Calc. Appl. Anal. 12, 3 (2009), 299-318.

[10] M. JLELI AND B. SAMET, Lyapunov-type inequatlities for a fractional differential equation with mixed boundary conditions, Mathemaical Inequalities and applications 18, 2 (2015), 443-451. 
[11] A. A. Kilbas, H. M. SRivastava And J. J. Trujillo, Theory and applications of fractional differential equations, Elsevier, Amsterdam, 2006.

[12] A. M. Lyapunov, Probleme général de la stabilité du mouvement, Ann. Fac. Sci. Univ. Toulouse. 2 , 9 (1907), 203-474.

[13] B. G. PachPatte, Mathematical Inequalities, North Holland Mathematical Library 1 (2005).

[14] N. PATHAK, Lyapunov-type inequality and eigenvalue estimates for fractional problems, Dissertation, Doctor of Philosophy, Southern Illinois University USA (2016).

[15] N. PATHAK, Lyapunov-type inequality and eigenvalue estimate for fractional problems of order $\alpha, \alpha \in$ $(2,3]$, Journal of Mathematical inequalities, (to be appear) (2019).

[16] I. Podlubny, Mittag-Leffler function: Calculates the Mittag-Leffler function with desired accuracy (File ID: No. 8738, mlf.m), MATLAB Central/File Exchange, 2005.

[17] Ji. RONG AND C. BAI, Lyapunov-type inequality for a fractional differential equation with fractional boundary conditions, Advances in Difference equations 82 (2015).

[18] S. G. SAmko, A. A. Kilbas And O. I. MARICHEV, Fractional integrals and derivatives, translated from the 1987 Russian original, Gordon and Breach, Yverdon.

[19] Ž. TOMOVSKI AND R. Hilfer, Fractional and operational calculus with generalized fractional derivative operators and Mittag-Leffler type functions, Integral Transforms and Special Functions 21, 11 (2010), 797-814.

[20] Ž. Tomovs KI, Generalized Cauchy type problems for nonlinear fractional differential equations with composite fractional derivative operator, Nonlinear Analysis, DOI: 10.1016/j.na.2011.12.034, (2012). 